\title{
The Selective Advantage of Complex Language
}

\author{
Robbins Burling \\ Department of Anthropology, University of Michigan
}

\begin{abstract}
The progressive evolution of the biological capacity to learn and use highly complex language is unlikely to be explained primarily by any subsistence or technological advantages that language offers. Rather, language probably served social purposes. In particular, two relationships could have driven selection in favor of increasingly complex language. First, in most or all societies, those who rise to positions of leadership tend to be recognized as having high linguistic skills. Second, in the kinds of society in which language must be presumed to have evolved, leaders tend to raise more children to maturity than do other people. Together, these two relationships would give a longterm selective advantage to increasingly skillful speakers.
\end{abstract}

Key Words: Evolution; Language; Leadership; Oratory; Individual Differences.

\section{LANGUAGE IN PREURBAN SOCIETY}

I

n the extensive, albeit speculative, literature on the evolutionary origins of language (e.g., Harnad, Steklis, and Lancaster 1976; Wescott 1974; de Grolier 1983; see also the massive bibliography in Hewes 1975), the adaptive advantages that would lead to the selection of linguistic ability seem to have been taken largely for granted. Where selection for language has been considered at all, the presumption has usually been that language would be an obvious advantage for gatherers and hunters, who needed to cooperate as they entered a subsistence niche not previously occupied by hominoids. Language ability, it has been supposed, would have been useful both in planning and coordinating the food quest itself and in reaching agreement upon the location of rendezvous points and central base camps (e.g., Lancaster 1968, p. 454; Hewes 1974, p. 15ff; Peters 1974, p. 89ff).

Such factors seem plausible as encouraging the first stages in the emergence of language but they offer little explanation for the peculiarly complex

Received April 8, 1985; revised August 6, 1985.

Address reprint requests to: Robbins Burling, Department of Anthropology, 1054 L.S. \& A.

Building, The University of Michigan, Ann Arbor, MI 49109.

Ethology and Sociobiology 7: 1-16 (1986)

(C) Elsevier Science Publishing Co., Inc., 1986

52 Vanderbilt Ave., New York, New York 10017

$0162-3905 / 86 / \$ 03.50$ 
type of language of which modern humans are capable. Why would a simpler language, perhaps something more like a rudimentary pidgin, not have been entirely adequate for subsistence purposes in the kinds of societies in which language evolved? Remarkably little attention has been given to the selective advantages offered by the baroque syntax or by the enormous vocabulary of near synonyms that are characteristic of all human languages today. To a modern and highly verbal linguist, the advantages of being able to talk in a complex and nuanced way may seem so obvious as hardly to invite discussion. Nevertheless, the selective pressures that would have fostered the development and perpetuation of such complex linguistic forms should by no means be taken for granted. In this article I will not be concerned with the initial emergence of the first stages of human language, but I will suggest a selective mechanism that might have driven the continued evolution of an increasingly complex language once the process had been launched.

The earliest remains of writing persuade us that languages of a fully modern degree of complexity were spoken at the time of the urban revolution, five or six thousand years ago, and archeological and fossil remains suggest that, in all likelihood, they were already spoken as early as the beginning of the upper Paleolithic, about 30,000 years ago. Only a certain robustness distinguishes fossil hominids of that era from modern humans, and it is difficult to doubt the capacity of those who left such remains for handling languages of the type and complexity that we know today. We must suppose, therefore, that the evolution of the biological capacity for learning and using a language of the modern type took place earlier in small and technologically simple societies, primarily those in which subsistence was based upon gathering and hunting. When we consider the forces that would have promoted the selection of individuals capable of using a lexically, syntactically, and phonologically complex language, therefore, we must consider the conditions of life in the small preurban and preagricultural societies that characterized human life for the first several million years of our time on earth. It was in such societies that language began, and it was also in such societies that increasingly complex language came to be used.

We can agree that some degree of language would be useful in a hunting and gathering adaptation, but it is not clear that such an adaptation would benefit in any way from a language having the high degree of complexity shown by all modern human languages. Excellent coordination in hunting could be achieved with a far less intricate language than ours. As has often been pointed out, members of some predatory species achieve effective cooperation in hunting with no language at all (Schaller 1972). In the direct and personal kinds of attack and defense that faced our evolving ancestors, the noise of talking must often have been more dangerous than total silence, and an intricate language would have been of little use. A single word or a single cry would have been more useful when warning a fellow australopithecine of an attacking lion than a paragraph of polished prose. Even today, when precise coordination under stressful conditions is required, we usually 
strip our language down to unambiguous essentials. To minimize misunderstanding we deliberately avoid linguistic complexities. "Duck!" is more effective than "Please lower your head in order to avoid that flying rock."

Language would have been more useful for initial planning of foraging and hunting than for actually conducting these activities, but a few hundred words, rather than the thousands of subtle near synonyms found in all modern languages, together with a bit of loose syntax and the kind of pointing that accompanies all language, should have been quite enough to tell others about the location and condition of berries and roots or the probable movements of animals. A complexly nuanced language does not seem to offer any special advantage for such activities. We are, then, left with a puzzle. If highly complex language is not needed for subsistence, what alternative selective pressures might have encouraged its emergence? Why do we have languages that are capable of elaborate phrases if simple phrases would have served as well in the kinds of societies in which language evolved?

Perhaps the education of the young in subsistence techniques would call upon more subtle linguistic skills than the practice of subsistence among mature adults. Words might supplement demonstration and observation of technological skills even if the actual use of these skills among adults would no longer need many words. The pedagogical use for language, like its use in hunting, has an initial plausibility, and it is certainly true that in our own society we make extensive use of language in technical education. In hunting bands and village communities, however, education for subsistence, like the practice of subsistence, could certainly be accomplished with a far less complex or subtle language than the people who live in these communities can actually use (Hewes 1974, p. 18; Bruner 1972, p. 701).

My own observations of language use among slash and burn farmers in northeastern India could, I believe, be duplicated by the observations of many ethnographers who have worked with hunters and gatherers or with people having a simple agricultural technology. ${ }^{1} \mathrm{My}$ Garo friends performed their technical tasks with a minimum of verbal coordination. People knew what needed to be done, knew how to do it, and knew when to do it. The minimum degree of coordination that was technologically required could easily have been achieved with a pidgin-like language of restricted vocabulary and simple sentence structure. Even the technical education of the young required only a modest use of language. I wanted to learn the technical skills of my hosts and, in my Western way, I would occasionally ask someone to explain how to tie a knot or how to hold a knife when cutting bamboo. About the only technical instruction I could ever elicit, however, would come when a man would reach for my tool, demonstrate the manner in which the job should be done, and then hand back the tool along with with the injunction: "Do it like that." This was also about all that children received

${ }^{1}$ I worked in the Garo Hills, then administratively a semiautonomous district of Assam, India, in the mid 1950s. I remain profoundly indebted to the Ford Foundation, which supported my field work. 


\section{R. Burling}

in the way of technical education. Children did learn many other things with the help of language-what would happen if they were impolite to their mother's brother, how to placate the spirits, which cousins are improper marriage partners-but subsistence and technical activities required little language either in use or in transmission to the next generation.

In a poor village near Varanasi in the State of Uttar Pradesh in India, I was once able to observe a young deaf mute woman of about 18 . She had grown up in a family of meager literacy and, so far as I am aware, she had received no formal education. Having had no contact with other deaf mutes, she had had no opportunity to learn a conventional sign language, though, of course, she communicated with other members of her family with homesigns of their own devising. In spite of her handicap and lack of formal education, this young woman performed many tasks with apparent ease and normality. She dressed herself as other women of her age dressed. She helped with the cooking. She went to the fields and helped with the cultivation. So far as I could tell, she easily pulled her own weight in subsistence activities. Of course she was cut off from large segments of the culture, but the absence of a nuanced language hardly cut her off at all from its subsistence or technical aspects.

In preurban band and village communities, where technology can be easily seen and understood, and where it can be learned by direct imitation, it does not require the subtle kind of language that all human societies possess. The evolutionary processes that took place in societies of this sort seem to have endowed us with more language than these societies could have used. If subsistence needs were not the driving force behind the development of language, we must wonder what other advantages might have led to its selection? I will return to this question below.

\section{LINGUISTIC VARIABILITY}

Selection can occur only when the trait under selection is variable and when some, at least, of its variation is the result of genetic variability. This has to mean that, during the period when the ability to use increasingly complex language was evolving, individuals varied from one another in their inherited capacity for language. To attribute individual differences in language ability to genetic differences violates the egalitarian ideology that most linguists hold dear. Nevertheless, the capacity for language surely did evolve, and it could not have done so without a variable genetic base upon which selection could work. The genetically based differences in linguistic ability, moreover, must have contributed to differential reproductive success.

The bias against searching for genetically based differences in linguistic skills is a strong one, and linguists have been reluctant to give any attention at all to individual differences. The sociolinguists have recently introduced a new interest in linguistic variability to the field, but even they have usually 
stopped short of examining genuinely individual differences. They have been willing to ask how the language of one narrowly defined social group, such as black middle-class children in a particular grade of a particular school, differs from the language of their otherwise comparable white classmates, but they have been leery about the last step-asking how two particular individuals differ from one another.

There are, to be sure, exceptions to this self-imposed restriction. The study of aphasia and other speech abnormalities necessarily involves the investigator in idiosyncratic linguistic traits, and a more general approach to individual language differences is found in Fillmore, Kempler, and Wang (1979). As the editors begin their introduction to this pioneering set of articles, they pose a number of questions that are notably unconventional among linguists:

People can differ greatly, and sometimes obviously, in the ways they use and control their language. Even with the same communicative goals, speakers will vary in many ways in their language performance, whether it is in the choice of words or intonation patterns, in the pacing of their utterances or in turn-taking strategies, or in the coherence or effectiveness of the total performance. We have wondered how such individual differences should be understood; in particular, we have wanted to learn how such differences could be seen as relating to social, psychological, or biological parameters. In what ways does personality determine, and in what ways is personality determined by, an individual's language resources? How and why do cultures value language fluency differently? How does our own culture identify, assess, and cultivate language ability? Does the observed variation in language ability have any basis in biological equipment? (p. 1).

I find these to be important though radical questions for linguists to be posing. The remarkably varied background of the research presented in the papers assembled by Fillmore, Kempler, and Wang and the tentative nature with which many authors present their results also confirm my belief that this is unfamiliar terrain. The contributors have addressed what $I$ take to be important issues, but in this first attempt they could hardly have been entirely clear, to say nothing of united, on the best means of doing so.

The more orthodox linguistic attitude about variability is represented by Chomsky's (1965, p. 3) explicit injunction that "Linguistic theory is concerned primarily with an ideal speaker-listener, in a completely homogeneous speech-community . . .' but this attitude, if not its explicit formulation, reaches back far before Chomsky. Linguists have seen language as a shared system, and even the finest grained sociolinguistic studies have stopped short of attributing linguistic characteristics to the individual. For the most part, linguists have systematically, even deliberately, ignored the possibility that individuals might differ in their linguistic ability. We have repeatedly asserted that all normal human beings learn to speak the language of their community, and we have rarely stopped to wonder whether all these normal people speak in exactly the same way. We have examined the commonalities of a language, not the individual differences. 
There are good reasons for the skittishness that many of us have felt when facing the possibility of individual differences in language ability. The measurement of linguistic skills is a big business in the United States. Advancement in both education and employment often rests on the results of tests that are intended to measure verbal aptitude. Linguists have found much to criticize in these tests, for they reduce what must be a multitude of separate skills to simplistic global measures, and they ignore the reality of dialect variation (Wolfram 1976). They are surely biased in favor of the fortunate children of the middle class. The serious difficulties posed by any attempt to sort out truly individual differences from differences that reflect class, ethnic membership, bilingual background, age, sex, or an apparently limitless range of other sociological variables have made many linguists skeptical of the whole enterprise. The manifestly dangerous biases of so many verbal aptitude tests have even encouraged some of us to throw our hands up in horror at the very suggestion that aptitude differences can be measured or that they even exist. Even if they do exist and even if they can be measured, it may seem prejudicial to recognize or to talk about them.

The refusal to acknowledge individual differences, however, runs up against some other stubborn intuitions and observations. All those who are not linguists seem to have utter confidence that the people they know differ substantially in their linguistic skills. When not wearing their professional hats, even linguists describe their acquaintances as "articulate," "fluent," "taciturn," "'glib," "slow spoken," "'a polished speaker," or "a master of malapropisms." Not only in our society, but very likely in other societies as well, people recognize some among their fellows as having outstanding linguistic skills of one sort or another-as arguers, orators, raconteurs, bards, punsters, rhyme makers, or, in literate societies, as writers. It is, I suspect, a universal characteristic of human societies that individual differences in linguistic ability are recognized, and it also appears to be universal, or very nearly so, that high linguistic ability is admired. The particular linguistic skills that are most admired probably vary considerably from one society to another, however, and it is surely the case that there are several different kinds of linguistic skills. The simplifications implicit in verbal aptitude tests that reduce all variability to a single scale seem totally unwarranted, but the conclusion that there are no individual differences at all seems equally misguided.

Individual differences, of course, can be of two types. On the one hand there are differences that seem to be rankable along some scale, as more or less advanced, as demonstrating greater or lesser linguistic ability, as allowing more or less complexity, as better or worse for some purpose. On the other hand there are nonrankable differences, such as inconsequential variability in pronunciation or even voice quality, special development of some arJeas of vocabulary, or idiosyncratic differences in syntactic detail. Of the two, linguists have found nonranked differences safer to investigate. We may be able to agree that people exhibit all sorts of idiosyncrasies in their 
speech while denying that these reflect any underlying differences in ability or contribute in any way to differential success at any activity. In spite of the phrase "language ability" that is included in the title of the collection of articles edited by Fillmore, Kempler, and Wang, and repeated several times in their introduction, a good proportion of their contributors take refuge in the safer topic of nonranked differences that seem independent of anything we would call "ability." They thereby avoid the issue of ability altogether.

If, however, we suppose our language to be in any way "better," " more developed," "more complex," or "capable of more subtlety" than the language of our ancestors of, let us say, two million years ago, we have to be concerned with rankable differences. It is only if individuals have differed in rankable linguistic abilities that evolution in the direction of higher ranked abilities could have taken place. Surely there was an evolutionary trend through time in such matters as the size of vocabulary that individuals could control and in the complexity of grammatical detail that they could handle. This evolution must have been built upon differences that were ordered along these dimensions within once living populations. In what follows, therefore, I will not be concerned with nonrankable idiosyncratic differences and will of necessity focus upon the more sensitive issue of rankable differences in linguistic ability. Most specifically I will be concerned with those aspects of rankable linguistic abilities that reflect, at least in part, genetic variability. I do not see how we can talk about the evolution of language unless we are willing to admit that individuals have differed in their inherited linguistic abilities.

If we are willing to grant that individuals vary in some dimensions of their language ability, and if we will grant that some of this variability must, in part, reflect genetic differences, we need only extrapolate backward to our ancestors of thousands and millions of years ago to feel that there must have been ample variability upon which selection could operate. Indeed, those who have worked with chimpanzees in recent decades have noted clear individual differences in their ability to acquire signs (Fouts and Couch 1976; Premak 1983). What remains is to propose a mechanism that would have selected in favor of those individuals who were capable of handling more complex language than most of their contemporaries.

\section{SELECTIVE ADVANTAGES}

Having tried to cast doubt upon subsistence and technical education as the primary areas that would favor the selection of high language abilities, I will offer an alternative and suggest that the selective advantages of language are to be found in the social rather than the technological sphere of human life. Specifically, I suggest that in pre-urban societies, and perhaps even in our own, language in its delicately nuanced forms is used, not so much for 
basic subsistence tasks, as for establishing, maintaining, and refining social relationships. In much the same way as Jolly (1966) and Humphrey (1976) argue that our intelligence evolved as a means of dealing with other individuals and is, therefore, primarily a social intelligence, I suggest that it is when dealing with people, not material objects, that we call upon our richest linguistic resources.

It is in defining ourselves in relation to others, in conducting interpersonal negotiations, in competing, in manipulating, in scheming to get our own way, that the most subtle aspects of language become important. We need language for arguing our case, for claiming our rights, for leaving just the right degree of ambiguity, for outdoing our rivals in our many intricate forms of verbal competition, for talking our way out of uncomfortable situations. When disputes grow dangerous, we need language as an alternative to violence. We need our very best language for winning a lover.

When we look beyond subsistence activities, and consider interpersonal relationships as the primary arena for complex and modulated language, new and different selective mechanisms offer themselves as plausible. In particular, there are two relationships that may have been found quite generally in preurban societies and that, taken together, would give a selective advantage to high language ability. First, leaders are often acknowledged within their community to possess special and admirable linguistic abilities. Second, there is a widespread tendency for high-ranking men to father a larger than average number of children or to raise a larger proportion of their children to maturity. If better speakers become leaders and if leaders raise more children, we have a mechanism that would drive the selection for better linguistic skills. Do we have grounds for taking these relationships seriously? I turn to the second relationship first, since it is somewhat easier to justify.

The relationship between rank and the number of children is supported by several recent demographic studies in widely varying populations, and it can even be looked upon as the human expression of the much more widespread tendency for the dominant males of many species to produce more than their share of offspring. The best studied example is that of the Yanomamos, and Chagnon, Flinn, and Melancon (1979, pp. 317-319) give careful figures to show that Yanomamo headmen, due both to polygyny and to more prompt remarriage after the loss of an earlier wife, have more wives than the average male. Their figures also suggest that the average headman's wife has more children than do wives of other men, although this difference does not reach the level of statistical reliability. Chagnon, summarizing, says "Headmen, in particular, continue to acquire wives in their later life and tend to produce significantly larger numbers of offspring than other males" (Chagnon and Irons, 1979, p. 384).

Neel (1980, p. 283) argues that Yanomamo who become headmen tend, in a number of respects including language, to be more capable than the average male. He states that headmen father approximately twice as many children as other men, and he suggests that this differential reproduction is 
"the principal agent ... of the selection necessary to offset the dispersive factors just mentioned." The "dispersive factors" to which he refers result from the steady accumulation of deleterious mutations, which, he believes, help to prevent some men from becoming headmen.

In a very different society, William Irons (1979) shows that the wealthier men among pastoral Turkmen of Iran raise substantially more children than do the poorer men. His article does not specifically consider the relation of wealth and leadership, but it is likely that they go together.

There are several reasons for the reproductive success of high-ranking men. The most obvious is the widespread tendency for polygyny to be the special prerogative of men with high status. Men are capable, biologically, of siring very large numbers of offspring, and they are limited primarily by their restricted access to women. Those men who manage to command the reproductive powers of more than a single woman can easily produce extra children. In fact, it is a very general tendency in human populations, as indeed in animal populations (see, e.g., Clutton-Brock, Guiness, and Albon 1982), that males vary far more widely than females in the number of offspring they produce. A few human males father large numbers of children, while others are excluded from reproduction.

In addition, however, chiefs or others of high status command more human and material resources than do others, and they are often able to use these resources to benefit their own children. In this way, they may be better able to ensure the survival of their children to reproductive age. Daly and Wilson (1983, p. 333), citing Driver (1963), describe an area in central India where "the fertility of (monogamous) couples showed no relationship to the husband's income, but the number of surviving children increased with increasing affluence." Thus even in the absence of polygyny, we can expect that high status will tend to be reflected in a larger number of surviving children.

In view of the help that siblings give to one another, Neel $(1980$, p. 284) proposes that differential reproductive success should show up even more strongly in the grandchildren's generation than in that of the children. On the basis of computer simulation, he suggests that in a society like that of the Yanomamos, more than half the males can be expected to have no grandchildren at all. A few others, of course, would have very large numbers.

I have emphasized the reproductive success of men because of the greater variability in the numbers of children they produce. Since there is a strict ceiling on the number of children that a woman can bear, their reproduction is considerably less variable than that of men, at least in the first generation. This means that any discussion of reproductive potential tends to sound sexually biased to those sensitive to suggestions of male-female differences. In spite of the smaller variation in the numbers of children born to women, however, women with superior social skills should be able to help to accumulate more resources, and they might also be able to win more successful fathers for their children. In these ways, a woman's social skills 
should join with those of a man to affect the number of children who survive. Moreover, through their genetic contribution to their sons, women also contribute to the variable reproductive success of the next generation. All of this means that the variable genetic contribution of women also contributes to reproductive success, although that may become unambiguous only with the second generation (Hrdy and Williams 1983).

At any event, the reproductive variability of men is more quickly apparent than that of women, and it is thus easier to measure. Furthermore, since most formal positions of leadership have tended to be monopolized by men, it is also with men that we can most readily test the possibility that language, leadership, and reproduction are all related.

The relation between language ability and leadership is less easy to pin down than is the relation between status and numbers of offspring, but the impressions of a good many ethnographers make it seem plausible. Perhaps the most convincing array of evidence for the high language skills of leaders is found in Bloch (1975). The case studies in this collection suggest that in a remarkably wide range of societies, leaders are good talkers. Andrew Strathern (1975), for instance, in describing the people of Mount Hagen in the Western Highlands of Papua New Guinea, says:

A man can ... retain prominence . . . for long periods of time well into his old age and one of the resources he has at hand for doing so is his ability to speak (p. 186).

Prominent men are speech-makers. A man can raise numerous pigs and give many away in moka [ceremonial exchange] but he cannot effectively influence his fellow-men unless he can use speech persuasively . . . most bigmen are in fact good speakers, although some are much more persuasive and fluent than others (p. 187).

David Turton (1973) describes the very different society of the Mursi of pastoral East Africa, but his conclusions are similar:

One does not have to attend many meetings in a particular locality before coming to recognize the more influential men of the area. They are the speakers who are listened to without interruption and whose speeches tend to come toward the end of a debate, not because there is any set order of speakers, but because the very nature of their contributions reduces the need for further discussion (p. 173).

Since it is thus through consensus alone that public meetings reach agreement, it is not surprising that the most frequently mentioned attribute of an influential man is his ability to speak well in public (p. 176).

It is not only the tone of a speech, but also the skill with which it is constructed that seems to impress an audience. Mursi public speeches tend to be very allusive, simply because this is a small and fairly isolated language community, but some men appear to excel in the subtlety with which they employ allusions and images in their speeches, thereby achieving a terseness of style which is much appreciated by the audience (177). 
Admiration for high linguistic ability and the elevation of good talkers to positions of leadership is by no means limited to the kinds of societies with which anthropologists have been most familiar. In his study of early classic Greece, Havelock (1963) describes the relation of language and leadership in this way:

within limits, the community's leadership lay with those who had a superior ear and rhythmic aptitude, which would be demonstrable in epic hexameter. It would also however show itself in the ability to compose rhemataeffective sayings which used other devices besides the metrical, such as assonance and parallelism. Again, the good performer at a banquet would be estimated not exclusively as an entertainer but as a natural leader of man ... the effective judge or even general tended to be the man with the superior oral memory. . . . The general effect was to put a great premium upon the intelligence in Greek social transactions and to identify intelligence with power. By intelligence we specially mean a superior memory and a superior sense of verbal rhythm (p. 126).

These examples come from technologically more developed societies than those in which language evolved, but there seems no reason to suppose that the relationship between language and lcadership was any less significant in earlier societies. Although the resources of hunting and gathering societies did not ordinarily allow the kind of institutionalized chiefdoms sometimes found in more settled societies, they still included men of special influence and these men must have used skillful language in order to assert their leadership.

Although the examples that I have given refer primarily to language of the political arena, it is the more general human experience that people gain influence in all areas of life, in their families and among their friends as well as in the wider community, through their ability to argue their case verbally, to present themselves well with words. People exploit their ability in language as they compete with one another for social position, for sexual partners, and for power, and their recognized linguistic skills make some people appear to others as especially well qualified for positions of responsibility. It is the impression of many ethnographers that the influential men and women in the communities where they have worked tend to be particularly verbal. Even in our own society, of course, those who reach influential positions, not only in government but also in such spheres as business and education, tend to be recognized as highly verbal individuals. A technically skilled horticulturist, machinist, jeweler, sculptor, or dentist need not have strong verbal facility. A leader needs language.

As a social activity, of course, it is not enough that language is spoken. It must also be understood, or at least recognized and appreciated. Language that demonstrates a high order of ability would be of very little use if others in the community did not acknowledge its special qualities. To the extent that there is a genetic component in the ability to use language of high complexity, we can expect that, at least to some degree, high language ability will run in families. In maximizing their inclusive fitness, individuals might 
then be able to rely upon the corresponding linguistic capacities of near kinsmen. However, the exploitation of one's own linguistic capacities does not necessarily require that others share these capacities to the same degree. Those who use language are always able to understand a considerably wider range and variety of speech than they can use. All of us can understand words and all of us can understand dialects that we cannot produce. We are able to appreciate and be persuaded by those who speak more skillfully than we do ourselves. Nonpoets can be moved by poets.

The possibility that apes might be able to learn to understand, as opposed to produce, a certain amount of human spoken language has been rather lost in the enthusiasm for teaching them to sign. There is, however, a good deal of anecdotal evidence, and at least a bit of experimental evidence, that suggests that chimpanzees and gorillas can learn to understand some natural human language (Kellogg and Kellogg 1933; Fouts, Chown, and Goodwin 1976; Patterson 1978). This would suggest that when a few early hominids began to use the rudimentary antecedents of language they would have been understood by their fellows, even if the others were deficient in answering back. $\Lambda t$ any point in the evolution of language, we must suppose that some individuals could use more complex language than others. Quite possibly some families were able to profit by the special linguistic ability of a number of their members. We need not suppose, however, that problems of limited understanding posed any serious impediment for those who were at the forefront of linguistic evolution. Most others should have been able to understand the language and appreciate the linguistic ability of the most skillful, even when they could not equal that ability themselves.

In fact, we may suspect that the selective pressures favoring better language comprehension were at least as strong, and quite possibly stronger, than the selective pressures favoring more skillful production. There are manifest advantages in being able to use the gestures and noises of other individuals in order to predict their intentions. The advantages of revealing one's own intentions by producing gestures or noises are much less clear. Although selection must have favored good speakers, it must also have favored those who were able to conceal their intentions. The ability to communicate information seems less advantageous to the individual than the ability to manipulate, though one way to manipulate others, of course, is to provide them with selected information (Krebs and Davies 1984).

One objection that might be raised against my argument is that it is the leaders themselves who define what the community accepts as "good"' language. If "good" language is, by definition, whatever the leaders speak, then their language is no sign of special talent. This argument, of course, is familiar in our own society, where linguists insist that the popular disdain for nonstandard dialects is simply a reflection of their disdain for those who speak them. No narrowly linguistic justification can be found for the admiration directed toward standard language (Labov 1969).

To admit that the upper classes are able to define "correct" (i.e., "stan- 
dard") language in our own society, however, does not dispose of individual differences in linguistic ability. To insist that all dialects are linguistic equals is not the same thing as the claim that all individuals are linguistic equals. Among those who adhere closely to the norms of standard English, some can use their language more successfully than others to manipulate their social environment. The same is true for nonstandard speakers. The kinds of linguistic differences that $\mathrm{I}$ am considering in this article are those that separate individuals from one another, not those that separate social groups.

A more serious objection to my thesis is that the demonstration of high linguistic ability is less a prerequisite of leadership than its consequence. Once in office a man may have an opportunity both to acquire linguistic skills and to exhibit linguistic talent that had previously lain dormant. Perhaps those who rise to leadership must talk on occasions that make them appear to have special skills. The apparent talent of leaders would then be an illusion. To sort out fully what is cause and what is effect in the relation of leadership and language requires more careful ethnographic studies than are now available, but the question is, at least, an empirical one. Unlike so many of the speculations about linguistic evolution, data should be obtainable that would bear upon the question. In the meantime, the examples we already have do appear to suggest that it helps to have linguistic talent to start with. Observers who have addressed the question write as if the leaders they have known brought their skills to office with them.

If leadership requires skillful language and if leaders have more progeny than others, we have identified a reasonably direct selective mechanism that would foster language of an increasingly complex sort. I do not, of course, mean to argue that this is the exclusive selective mechanism for linguistic evolution. Many other factors could have operated simultaneously. Nor do I mean to argue that all leaders in all societies are linguistically talented, or that no other attributes are important in the rise to leadership. There have surely been times and places where prowess in hunting or in fighting has been a more important quality for a leader than language, and we can certainly find tongue-tied leaders. Still, the importance of other factors does not eliminate language, for selection can respond simultaneously to many different pressures.

Nor does my argument deny that people of great linguistic talent can be found outside of the ranks of leaders. All that is needed for the mechanism I suggest to be effective is that the average leader in the average society have slightly more verbal facility and slightly more children than other men. Evolution, even human evolution, has been going on for a long time. Over the course of enough generations, even small and inconsistent differences in reproductive success can accumulate until they yield large effects.

It would, of course, be more satisfactory if we could establish a direct connection between linguistic ability and numbers of children. The intervening variable of leadership complicates the equation. It is not entirely satisfying to note that Greek leaders were good talkers and that Yanomamo 
leaders have more children. We would also like to know about the reproductive success of Greek leaders and the linguistic talents of Yanomamo leaders. It would also be more satisfactory if we could establish this relationship in the types of hunting and gathering societies where the ability to speak evolved, but there are few such societies surviving and ethnographic evidence is lacking. On such points, all I can do is plead for more complete data.

Unless one wants to deny that language evolved, however, I do not see how we can escape the presumption that high linguistic skill conferred some sort of selective advantage among our ancestors. Most of the advantages of language seem to be social, and it is in the social sphere that the advantages of some individuals over others seems to lie. Almost everyone would appear to have sufficient linguistic ability to carry out the technological tasks of a preurban society, but whenever there is competition, whether for leadership, for women, or for wealth, there is no limit to the linguistic refinements that could give one individual an advantage over another. Once it became advantageous among evolving humans to command a language that is superior to that of one's fellows, there could have been a steady and long-term pressure for ever more powerful linguistic ability.

The evolutionary mechanism that I have proposed offers no solution to the puzzle of how language arose in the first place, but it does suggest an engine that, once started, could have driven the evolution of the capacity for language over a very long period of time, quite plausibly for several million years. During this period, language could have steadily improved without the improvements ever playing any central role in subsistence. Eventually, however, an increasingly complex language must have implied an increasing power of conceptualization, and this may have preadapted the users of complex language to a radically different kind of life than that in which language first evolved.

The cognitive abilities entailed by an improving language helped to bring about a species that was capable, first, of producing the refined art and tool assemblages that we find in the upper Paleolithic, and capable, later, of inventing the revolutionary civilization that began with agriculture and developed into urban life. The urban revolution would hardly have been possible had the biological and cognitive capacities for language not evolved first. With cities came trade, marketing, writing, record keeping, codified legal systems, hierarchical status, an increasing division of labor, bureaucracy, specialists in religious ritual, the accumulation of recorded knowledge, systematic learning, formal education, and science. All these new activities depend crucially upon a kind of language that had evolved in an earlier era. Language, selected as a means for conducting increasingly refined social relationships, came finally to permit the vastly more complex organization of modern human society. Evolved as a delicate instrument for establishing and modulating ever more intricate relationships among human 
beings, language continues to serve as such an instrument in the societies in which we live today.

I am heavily indebted to numerous friends and colleagues who read earlier drafts of this paper and who did their best to dissuade me from my wilder and more confused ideas: A. L. Becker, Penelope Eckert, Virginia Guilford, Mark V. Flinn, Anne Hvenekilde, Frank Livingstone, Bruce Mannheim, Thomas Moylan, Emanuel Polioudakis, Roy A. Rappaport, Virginia Vitzthum, and Aram A. Yengoyan. Three reviewers from this journal, one of whom, Robert Seyfarth, revealed his identity to me, offered exceedingly valuable comments and suggestions. I am particularly grateful to Richard Wrangham, who took me seriously when I first began to think about the ideas I offer here, and to Milford Wolpoff who kept arguing with me right up to the very last.

\section{REFERENCES}

Bloch, Maurice (Ed) Political Language and Oratory in Traditional Society. New York, London: Academic, 1975.

Bruner, Jerome S. Nature and uses of immaturity. American Psychologist 27: 687-708 (1972). Chagnon, Napoleon A., Flinn, Mark V., Melancon, Thomas F. Sex ratio variation among the Yanomamo Indians. In Evolutionary Behavior: Anthropoligical Perspective, Napoleon A. Chagnon and William Irons (Eds.). North Scituate, MA: Duxbury, 1979, pp. 290 320.

_- Irons, William (Eds.) Evolutionary Behavior: Anthropological Perspective. North Scituate, Ma: Duxbury, 1979, p. 384.

Chomsky, Noam Aspects of the Theory of Syntax. Cambridge: M.I.T. Press, 1965.

Clutton-Brock, T.H., Guinness, F.E., Albon, S.D. Red Deer: Behavior and Ecology of Two Sexes. Chicago: University of Chicago Press, 1982.

Daly, Martin, Wilson, Margo Sex, Evolution, and Behavior, 2nd ed. Boston: Willard Grant, 1983.

de Grolier, Eric (Ed.) Glossogenics: The Origin and Evolution of Language. New York: Harwood, 1983.

Driver, E.D. Differential Fertility in Central India. Princeton: Princeton University Press, 1963.

Fillmore, Charles J., Kempler, Daniel, Wang, William S-Y (Eds.) Individual Differences in Language Ability and Language Behavior. New York: Academic, 1979.

Fouts, Roger S., Chown, B., Goodwin, L. Transfer of signed responses in American Sign Language from vocal English stimuli to physical object stimuli by a chimpanzee ( $P$ an). Learning and Motivation 7: 458-475 (1976).

- Couch, Joseph B. Cultural evolution of learned language in chimpanzees. In Communicative Behavior and Evolution, Martin E. Hahn and Edward C. Simmel (Eds.). New York: Academic, 1976, pp. 141-161.

Harnad, Steven R., Steklis, Horst D., Lancaster, Jane (Eds.) Origins and Evolution of Language and Speech. Annals of the New York Academy of Sciences, Vol. 280. New York: New York Academy of Sciences, 1976.

Havelock, E. Preface to Plato. Cambridge, MA: Harvard University Press, 1963.

Hewes, Gordon W. Language in early hominids. In Language Origins, Roger W. Wescott (Ed.). Silver Springs MD: Linstock, 1974, pp. 1-33.

- Language Origins: A Bibliography, 2 nd revised and enlarged edition. 2 volumes. The Hague: Mouton, 1975.

Hrdy, Sarah Blaffer, Williams, George C. Behavioral biology and the double standard. In Social Behavior in Female Vertebrates, Samuel Wasser (Ed.). New York: Academic, 1983, pp. 3-17.

Humphrey, N.K. The social function of the intellect. In Growing Points in Ethology, P.P.G. Bateson and R.A. Hinde (Eds.). New York: Cambridge University Press, 1976, pp. 303-317. 


\section{R. Burling}

Irons, William Culture and Biological Success. In Evolutionary Behavior: Anthropological Perspective, Napoleon A. Chagnon and William Irons (Eds.). North Scituate, MA: Duxbury, 1979.

Jolly, Alison Lemur social behavior and primate intelligence. Science 153: 501-506 (1966).

Kellogg, W.N., Kellogg, I.A. The Ape and the Child. New York: McGraw-Hill, 1933.

Krebs, John R., Davies, N.B. Animal signals: Mind reading and manipulation. In Behavioral Ecology: An Evolutionary Approach, 2nd ed., John R. Krebs, and Richard Dawkins (Ed.). Sunderland, MA: Sinauer, 1984, pp. 380-402.

Labov, William The Logic of Nonstandard English. In Linguistics and the Teaching of Standard English to Speakers of Other Languages or Dialects. Monograph Series on Languages and Linguistics, No. 22. James E. Alatis (Ed.). Washington, D.C.: Georgetown University Press, 1969, pp. 1-43.

Lancaster, Jane Primate communication systems and the emergence of human language. In Primates: Studies in Adaptation and Variability, Phyllis C. Jay (Ed.). New York: Holt, Rinehart, \& Winston, 1968, pp. 439-457.

Neel, James V. On being headman. Perspectives in Biology and Medicine 23(2): 277-294 (Winter 1980).

Patterson, F.G. The gestures of a gorilla: Language acquisition in another pongid. Brain and Language 5: 72-97 (1978).

Peters, Charles R. On the possible contribution of ambiguity of expression to the development of proto-linguistic performance. In Language Origins, Roger W. Wescott (Ed.). Silver Springs, MD: Linstok, 1974, pp. 83-102.

Premak, David The codes of man and beast. Behavioral Brain Sciences 6: 125-167 (1983).

Schaller, George B. The Serengeti Lion. Chicago: University of Chicago Press, 1972.

Strathern, Andrew Veiled speech in Mount Hagen. In Political Language and Oratory in Traditional Society, Maurice Bloch (Ed.). New York, London: Academic, 1975, pp. 185203.

Turton, David The relationship between oratory and the exercise of influence among the Mursi. In Political Language and Oratory in Traditional Society, Maurice Bloch (Ed.). New York, London: Academic, 1975, pp. 163-183.

Wescott, Roger W. (Ed.). Language Origins. Silver Springs, MD: Linstok, 1974.

Wolfram, Walt Levels of sociolinguistic in testing. In Black English: A Seminar, Deborah Sears Harrison and Tom Trabasso (Eds.). Hillsdale, NJ: Lawrence Erlbaum Associates, 1976. 